\title{
Inhibition of Adenylate Cyclase of Regeneration- Competent Cells of Nervous Tissue: a Novel Approach for the Treatment of Alcoholic Encephalopathy
}

\author{
Gleb Nikolaevich Zyuz'kov 1,* (D), Larisa Arkad`evna Miroshnichenko 1(D), \\ Tatyana Yur`evna Polykova ${ }^{1}$ (D), Larisa Alexandrovna Stavrova ${ }^{1}$ (D), Elena Vladislavovna Simanina ${ }^{1}$ (D) \\ 1 Laboratory of Pathological Physiology and Experimental Therapy, Goldberg Research Institute of Pharmacology and \\ Regenerative Medicine, Tomsk National Research Medical Center, Russian Academy of Sciences, Tomsk, Russia, 3 Lenin \\ Prospect, Tomsk, 634028, Russia; nii@pharmso.ru; \\ * Correspondence: zgn@pharmso.ru;
}

Scopus Author ID 6508338421

Received: 29.04.2021; Revised: 26.05.2021; Accepted: 30.05.2021; Published: 9.06.2021

\begin{abstract}
Researching new pharmacological targets and developing highly effective drugs to treat ethanol-induced encephalopathy is an urgent task of neuroscience and pharmacology. The work aimed to study the neuroprotective and neuroregenerative effects of adenylate cyclase (AC) inhibitors in modeling alcoholic encephalopathy in experimental animals. The morphofunctional repair of the brain and the functioning of progenitors (neural stem cells (NSC) and neuronal-committed progenitors (NCP)) and neuroglial cells (astrocytes, oligodendrocytes, microglial cells) of the subventricular zone of the cerebral hemispheres (SVZ) have been investigated. A significant correction of brain morphological changes, disorders of exploratory behavior, and conditioned reflex activity in laboratory animals under the influence of the AC inhibitor were revealed. Increased proliferation of both types of progenitor cells and accelerated differentiation of the NSC were observed when AC inhibitors were administered to mice with neurodegeneration. Improved neurotrophin secretion by astrocytes and microglia was also identified. The findings show the promise of developing a novel approach to treating alcohol-induced encephalopathy with AC inhibitors.
\end{abstract}

Keywords: progenitor cells, neuroglia, cAMP, adenylate cyclase, alcohol-induced encephalopathy, regenerative medicine.

(C) 2021 by the authors. This article is an open-access article distributed under the terms and conditions of the Creative Commons Attribution (CC BY) license (https://creativecommons.org/licenses/by/4.0/).

\section{Introduction}

Systemic ethanol abuse can develop many serious disorders, including irreversible, neuropsychiatric, and neurological disorders - alcoholic encephalopathy [1, 2]. Neurodegeneration, in this case, is a result of the effect on the central nervous system (CNS) of a multifactor pathogenic biochemical continuum. This is a consequence of the change in during prolonged intoxication of the body's ethanol [3, 4]. In many cases, this is accompanied by deregulation of the internal organs, which contributes to the progression of the disease. Existing approaches to pharmacotherapy of alcohol-induced encephalopathy consist of modulating the functions of mature cell elements of neural tissue preserved in pathology conditions. However, this concept of treatment in some cases is untenable [5, 6]. Therefore, it is relevant to develop drugs for the therapy of ethanol-induced encephalopathy with principally new mechanisms of action. 
It is known that the dysfunction of the CNS when ethanol is used develops against the background of the loss of the neurogenesis ability of the nervous tissue [7, 8]. In this regard, it is promising to study the possibility of pharmacological stimulation of repair of affected brain structures by activating the functions of regeneration-competent cells of nervous tissue. The intensity of cell renewal processes in the CNS depends on the functional state of both postnatal progenitor cells [9] and glial elements [10]. Neural stem cells (NSC) and neuronal-committed progenitors (NCP)) can form de novo neurons, astrocytes, oligodendrocytes, and resident mesenchymal precursors, leading to microglia instead of dysfunctional and dead cells [11, 12]. Neuroglia, in turn, regulates neurogenesis due to the production of some humoral factors and the formation of direct intercellular contacts with progenitors and newly formed specialized cells [13].

It is known that cell functions are realized by the functioning of the intracellular signaling system represented by sequentially activated special proteins - signaling molecules [14]. One of the main signal transduction pathways is cAMP-dependent signaling $[15,16]$. In vitro experiments, an important role of cAMP and PKA was to regulate neural stem cell functions, including in ethanol-induced neurodegeneration. It has been shown that blockade of adenylate cyclase in NSC of long-term alcoholized animals increases proliferative activity [17]. However, it is known that balanced neurogenesis requires close coordination of the activation processes of multipotent NSCs and neuronal-committed progenitors [5, 12]. Also, an obligatory factor of adequate morphofunctional restoration of the CNS is a conjugation of these processes with the pronounced compensatory reaction of glial cells [10-12]. But to date, the possibility of stimulating the functions of NCP and neuroglia in ethanol-induced encephalopathy by targeting (selective blockade) of cAMP/PKA-signaling remains unknown.

The work aimed to study the neuroprotective activity of the adenylate cyclase (AC) inhibitor in modeling alcohol-induced encephalopathy. The pharmacological agent's mechanisms associated with the functioning of the progenitors of nervous tissue (NSC and $\mathrm{NCP}$ ) and glial cells secreting neurotrophins (astrocytes, oligodendrocytes, and microglia) were investigated.

\section{Materials and Methods}

\subsection{Chemicals and drugs.}

MACS Neuro Medium; anti-PSA-NCAM MicroBeads; anti-ACSA-2 MicroBead Kit; Anti-O4 MicroBeads; Anti-CD11b (Microglia) MicroBeads (all manufactured by Miltenyi Biotec, Germany); adenylate cyclase (AC) inhibitor «2',5'-dideoxy Adenosine» (SigmaAldrich, USA); hydroxyurea (Calbiochem, USA); dimethyl sulfoxide (Sigma-Aldrich, USA); plastic plates for cultural studies (Costar, USA).

\subsection{Animals and experimental design.}

All animal experiments were carried out following the U.K. Animals (Scientific Procedures) Act, 1986 and associated guidelines, EU Directive 2010/63/EU for animal experiments. The Institute's local Ethics Committee approved the study. Experiments were carried out on C57B1/6 mice ( $n=118)$ at the age of 2-2.5 months, weighing 20-22 g. Animals of the first category (conventional mice) were acquired from Goldberg Research Institute of Pharmacology and Regenerative Medicine (the Experimental Biological Models Department). Before the start of the experiments (10 days) and during the study period, the animals were 
kept in a vivarium $\left(20-22^{0} \mathrm{C}\right.$, humidity $\left.50-60 \%\right)$ in plastic cages $(10-15$ mice) following a normal diet, water ad libitum. To exclude seasonal variations from the parameters studied, all experiments were conducted in autumn-winter. The animals were taken out of the experiment (killed) by $\mathrm{CO}_{2}$ cameras.

We studied the influence of the AC inhibitor on orientation and exploratory behavior, conditioned reflex activity, and brain morphology of experimental animals after modeling alcoholic encephalopathy.

The AC inhibitor was injected 10 days after the last ethanol administration: subcutaneously once a day for 7 days at a dose of $15 \mathrm{mg} / \mathrm{kg}$. Later in the study design description, the day of initiation of the AC inhibitor injection is considered "day 1." The control mice were injected subcutaneously with a solvent $(0.2 \mathrm{ml}$ of $2 \%$ dimethyl sulfoxide $)$ in the same regimen and equivalent volume.

Before the first administration of the AC inhibitor on "day 1" and at 3, 7, 14, 21, 28 days after the start of the injection of the AC inhibitor, the neuropsychiatric status of animals (orientation and exploratory behavior and reproducibility of the conditioned passive avoidance response (CPAR)) was studied ( $n=34$ in the experimental and control groups). On the 7 th day after the initiation of the AC inhibitor administration, a histological examination of the brain was performed ( $n=10$ in the experimental and control groups). Using the cultural methods, on 1 (the cells for the study were taken before the first administration of the AC inhibitor), 3, 7, 14, 21 days after the start of the injection of the AC inhibitor, the content of NSC and NCP in the subventricular zone of the cerebral hemispheres (SVZ), their proliferative activity and the intensity of specialization (differentiation/maturation) were studied. Also, at this time, the production of neurotrophic growth factors by glial cells (astrocytes, oligodendrocytes, microglia) ( $n=10$ in the experimental and control groups) was investigated.

\subsection{Alcoholic encephalopathy modeling.}

Modeling of the ethanol-induced encephalopathy was carried out by oral administration of a $30 \% \mathrm{C}_{2} \mathrm{H}_{5} \mathrm{OH}$ solution (through a probe daily at a dose of $3 \mathrm{~g} / \mathrm{kg} /$ day for 8 weeks) $[5,12]$. In this case, instead of drinking water of free access, a 5\% ethyl alcohol solution was used. Cellular materials for the study were taken 10 days after the end of the introduction of ethanol in vivo. The control group (intact mice) under the same scheme per os injected distilled water in an equivalent volume (mice had free access to drinking water).

\subsection{Estimation of psychoneurological status.}

The psychopharmacologic effects of the AC inhibitor were evaluated using functional methods. The orientation and exploratory behavior were studied in the open field method [18]. Total, horizontal, and vertical locomotor activity, hole-board exploration, self-grooming, and defecation were evaluated in mice for 3 minutes. The values of the first minute and the next 23 minutes were studied separately. The CPAR test $[19,20]$ was used to evaluate the effect of the pharmacologic substance on mnestic cerebral function. This method is based on the reproduction of the acquired competence in passive avoidance of the electric stimulus $(0.45$ $\mathrm{mA}$ ) by mice in the dark compartment of a special camera. To do this, they had to be in the light compartment of the chamber, despite the innate preference of rodents for dark space. The development of the reflex was carried out 3 days after the introduction of the AC inhibitor. This experiment scheme made it possible to study the influence of the pharmacological 
substance on the formation, consolidation, and reproduction of the commemorative trace (engram) simultaneously. The reflex was considered to be developed if, during all 3 minutes of observation, the animal never visited the dark compartment or the latent time of entry exceeded 150 seconds [18-20].

\subsection{Histological study.}

Brain histological preparations were stained with hematoxylin and eosin. Prior to this, it was fixed in $10 \%$ neutral formalin, dehydrated in a series of alcohols with an increase in the concentration impregnated with paraffin and cut into pieces 4-5 microns thick [21]. The state of microvascularity of the meninges and brain, swelling of nervous tissue, presence of neurons with signs of degeneration, necrosis (hyperchromic nuclei, with vacuolar dystrophy) in the state of phagocytosis were evaluated.

\subsection{Determination of progenitors' functional activity.}

NSC was studied in the culture of unfractionated SVZ cells of the brain hemispheres. The neuronal-committed progenitors (NCP) sequence by "MIniMACS Cell Separator" (Miltenyi Biotec, Germany). To do this, the cells received PSA-NCAM ${ }^{+}\left(\mathrm{CD}^{+}{ }^{+}\right)$cells [22] (used appropriate sets of antibodies). The cells were adjusted to $10^{5} / \mathrm{ml}$ and incubated in MACS Neuro Medium (Miltenyi Biotec, Germany) for 5 days in a $\mathrm{CO}_{2}$ incubator at $37^{\circ} \mathrm{C}, 5 \%$ $\mathrm{SO} 2$ and $100 \%$ air humidity. The clonogenic cell content, mitotic activity and specialization intensity have been calculated. The NSC and NCP amount was determined by the yield in the respective cultures of colony-forming units (CFU, neurospheres containing more than 100 cells). The proliferative activity of the CFU was assessed by the method of cell suicide technic using hydroxyurea $(1 \mu \mathrm{M})[5,12]$. The number of CFU in the S-phase of the cell cycle was determined using the following formula: $\mathrm{N}=[(\mathrm{a}-\mathrm{b}) / \mathrm{a}] \times 100 \%$, where $\mathrm{a}-$ the amount of $\mathrm{CFU}$ from cells not treated with hydroxyurea; $b$ - the amount of CFU from hydroxyurea treated cells. The specialization (differentiation/maturation) intensity of the progenitors was determined by calculating the ratio of the corresponding cluster-forming units (CIFU, neurospheres of 30 100 cells) to CFU - the differentiation index $[9,17]$.

\subsection{Study of neurotrophic growth factors secretion by neuroglial cells.}

Single fractions of astrocytes (ACSA-2 + cells [23]), oligodendrocytes (O4 + cells [24]) and microglia (CD11b + cells [25]) were isolated from the subventricular region of the cerebral hemispheres by the immunomagnetic positive selection method. Appropriate antibody kits of Miltenyi Biotec, Germany, were used. The cells (at a concentration of $2 \times 10^{6} / \mathrm{ml}$ ) were incubated in MACS Neuro Medium (Miltenyi Biotec, Germany) for 2 days in a $\mathrm{CO}_{2}$ incubator at $37^{\circ} \mathrm{C}, 5 \% \mathrm{CO}_{2}$ and $100 \%$ air humidity to obtain conditioned media. To determine the secretory activity (neurotrophic growth factors production) of glial elements, the effect of supernatants from cells on the level of neurospheres formation (CFU) in the test system (culture of the SVZ unfractionated cells) was studied $[17,26]$.

\subsection{Statistical analysis.}

Statistical analysis was performed using one-way ANOVA, followed by Dunnett's, Wilcoxon's test for dependent samples, and Mann-Whitney test. The data are presented in the 
form of arithmetic means and standard errors (in tables) or confidence intervals (in figures, at $p=0.05)$. The significance level was $p<0.05$ [27].

\section{Results and Discussion}

\subsection{Characterization of the parameters in alcoholic encephalopathy.}

3.1.1. Psychoneurological status disorders.

Chronic ethanol intoxication resulted in pronounced changes in neuropsychiatric status. There was a significant increase in total motor activity, mainly due to the number of horizontal movements of mice in the open field during all study periods. Moreover, these changes were recorded both in the first minute of observation (on the 1,3, 7, 14, 21st day) and when determining this parameter in the 2-3 minutes (on the 1, 7,21st day) (Table 1).

Table 1. Parameters of orientation and exploratory behavior of intact C57B $1 / 6$ mice (1); mice after prolonged ethanol intoxication (2) and mice treated with an AC inhibitor after simulating alcoholic encephalopathy (3), arb. units $(\mathrm{M} \pm \mathrm{SEM})$

\begin{tabular}{|c|c|c|c|c|c|c|c|}
\hline Day & Groups & $\begin{array}{l}\text { Total } \\
\text { locomotor } \\
\text { activity } \\
\end{array}$ & $\begin{array}{l}\text { Horizontal } \\
\text { locomotor } \\
\text { activity } \\
\end{array}$ & $\begin{array}{l}\text { Vertical } \\
\text { locomotor } \\
\text { activity }\end{array}$ & $\begin{array}{l}\text { Hole-board } \\
\text { exploration }\end{array}$ & $\begin{array}{l}\text { Self- } \\
\text { grooming }\end{array}$ & Defecation \\
\hline \multirow{8}{*}{1} & \multicolumn{7}{|c|}{ Frist period (minute 1) } \\
\hline & 1 & $14.79 \pm 2.24$ & $8.33 \pm 1.72$ & $2.33 \pm 0.51$ & $3.27 \pm 0.80$ & $0.73 \pm 0.25$ & $0.13 \pm 0.09$ \\
\hline & 2 & $38.26 \pm 4.25 *$ & $25,27 \pm 1,95 *$ & $5,53 \pm 0,6^{*}$ & $5,40 \pm 0,92$ & $0,73 \pm 0,30$ & $0,33 \pm 0,16$ \\
\hline & 3 & $37.2 \pm 4.26^{*}$ & $26,2 \pm 1,34 *$ & $5,33 \pm 0,64 *$ & $5,47 \pm 0,85$ & $0,07 \pm 0,07$ & $0,13 \pm 0,09$ \\
\hline & \multicolumn{7}{|c|}{ Second period (minutes 2-3) } \\
\hline & 1 & $38.53 \pm 3.47$ & $21.0 \pm 2.81$ & $3,02 \pm 0,69$ & $11,33 \pm 2,89$ & $2,67 \pm 0,53$ & $0,53 \pm 0,19$ \\
\hline & 2 & $56.34 \pm 5.42 *$ & $34,47 \pm 4,51 *$ & $5,13 \pm 0,63 *$ & $13,80 \pm 2,21$ & $2,67 \pm 0,52$ & $0,27 \pm 0,15$ \\
\hline & 3 & $54.34 \pm 2.98 *$ & $31,07 \pm 3,32 *$ & $5,67 \pm 0,60 *$ & $15,78 \pm 2,85$ & $1,47 \pm 0,32$ & $0,33 \pm 0,21$ \\
\hline \multirow{8}{*}{3} & \multicolumn{7}{|c|}{ Frist period (minute 1) } \\
\hline & 1 & $25.66 \pm 2.36$ & $15,4 \pm 3,28$ & $3,53 \pm 0,65$ & $5,73 \pm 0,9$ & $0,73 \pm 0,21$ & $0,27 \pm 0,15$ \\
\hline & 2 & $36.46 \pm 3.01 *$ & $23,67 \pm 2,73 *$ & $6,33 \pm 0,48$ & $5,00 \pm 0,93$ & $1,33 \pm 0,36$ & $0,13 \pm 0,09$ \\
\hline & 3 & $28.60 \pm 2.97$ & $19,6 \pm 2,52$ & $3,33 \pm 0,56$ & $5,07 \pm 1,07$ & $0,53 \pm 0,17$ & $0,07 \pm 0,07$ \\
\hline & \multicolumn{7}{|c|}{ Second period (minutes 2-3) } \\
\hline & 1 & $39.74 \pm 2.57$ & $25,80 \pm 4,34$ & $5,60 \pm 0,83$ & $6,21 \pm 1,79$ & $1,27 \pm 0,33$ & $0,87 \pm 0,36$ \\
\hline & 2 & $33.34 \pm 5.56$ & $21,47 \pm 5,12$ & $4,00 \pm 0,63$ & $5,27 \pm 1,09$ & $1,87 \pm 0,45$ & $0,73 \pm 0,27$ \\
\hline & 3 & $38.72 \pm 4.37$ & $24,73 \pm 4,03$ & $5,87 \pm 1,14$ & $5,00 \pm 1,12$ & $2,27 \pm 0,51$ & $0,73 \pm 0,28$ \\
\hline \multirow{8}{*}{7} & \multicolumn{7}{|c|}{ Frist period (minute 1$)$} \\
\hline & 1 & $21.4 \pm 2.45$ & $15,67 \pm 1,70$ & $1,80 \pm 0,40$ & $1,80 \pm 0,50$ & $1,27 \pm 0,23$ & $0,60 \pm 0,27$ \\
\hline & 2 & $29.33 \pm 2.03 *$ & $22,67 \pm 1,91 *$ & $2,93 \pm 0,98$ & $2.87 \pm 1.00$ & $0.53 \pm 0.13$ & $0.33 \pm 0.16$ \\
\hline & 3 & $21.28 \pm 2.56 \#$ & $15,87 \pm 1,55 \#$ & $2,00 \pm 0,59$ & $2.07 \pm 0.48$ & $1.09 \pm 0.23$ & $0.27 \pm 0.12$ \\
\hline & \multicolumn{7}{|c|}{ Second period (minutes 2-3) } \\
\hline & 1 & $17.53 \pm 1.96$ & $11,8 \pm 1,63$ & $2,13 \pm 0,32$ & $1,73 \pm 0,58$ & $1,27 \pm 0,27$ & $0,60 \pm 0,29$ \\
\hline & 2 & $32.4 \pm 3.07 *$ & $21,00 \pm 3,06^{*}$ & $4,6 \pm 0,7 *$ & $2,87 \pm 1,0$ & $0,53 \pm 0,13$ & $0,33 \pm 0,16$ \\
\hline & 3 & $22.87 \pm 2.25 \#$ & $15,07 \pm 1,97 \#$ & $2,47 \pm 0,89$ & $2,07 \pm 0,48$ & $1,07 \pm 0,23$ & $0,27 \pm 0,12$ \\
\hline \multirow{8}{*}{14} & \multicolumn{7}{|c|}{ Frist period (minute 1 ) } \\
\hline & 1 & $20.47 \pm 2.01$ & $15,07 \pm 1,96$ & $2,27 \pm 0,42$ & $2,07 \pm 0,51$ & $0,93 \pm 0,18$ & $0,13 \pm 0,09$ \\
\hline & 2 & $28.06 \pm 1.96 *$ & $22,2 \pm 2,17 *$ & $2,20 \pm 0,48$ & $2,93 \pm 0,68$ & $0,53 \pm 0,19$ & $0,20 \pm 0,11$ \\
\hline & 3 & $21.34 \pm 2.43 \#$ & $16,27 \pm 2,77 \#$ & $2,47 \pm 0,49$ & $1,87 \pm 0,40$ & $0,60 \pm 0,21$ & $0,13 \pm 0,09$ \\
\hline & \multicolumn{7}{|c|}{ Second period (minutes $2-3$ ) } \\
\hline & 1 & $25.73 \pm 2.41$ & $17,8 \pm 2,28$ & $4,33 \pm 0,90$ & $2,00 \pm 0,49$ & $1,13 \pm 0,19$ & $0,47 \pm 0,17$ \\
\hline & 2 & $26.26 \pm 2.22$ & $18,80 \pm 2,43$ & $2,33 \pm 0,58$ & $3,93 \pm 1,08$ & $0,80 \pm 0,20$ & $0,40 \pm 0,19$ \\
\hline & 3 & $27.21 \pm 3.97$ & $19,27 \pm 4,4$ & $3,20 \pm 0,88$ & $2,79 \pm 0,48$ & $1,27 \pm 0,36$ & $0,67 \pm 0,21$ \\
\hline \multirow{8}{*}{21} & \multicolumn{7}{|c|}{ Frist period (minute 1 ) } \\
\hline & 1 & $16.40 \pm 1.41$ & $13,53 \pm 1,29$ & $1,40 \pm 0,61$ & $0,87 \pm 0,29$ & $0,53 \pm 0,17$ & $0,07 \pm 0,07$ \\
\hline & 2 & $22.86 \pm 1.39 *$ & $19,41 \pm 1,51 *$ & $1,40 \pm 0,35$ & $0,93 \pm 0,30$ & $0,73 \pm 0,18$ & $0,40 \pm 0,19$ \\
\hline & 3 & $18.73 \pm 1.57$ & $14,0 \pm 1,46$ & $1,21 \pm 0,43$ & $0,93 \pm 0,34$ & $0,47 \pm 0,17$ & $0,13 \pm 0,09$ \\
\hline & \multicolumn{7}{|c|}{ Second period (minutes 2-3) } \\
\hline & 1 & $17.00 \pm 1.72$ & $10,20 \pm 1,42$ & $2,87 \pm 0,92$ & $2,13 \pm 0,58$ & $1,00 \pm 0,20$ & $0,8 \pm 0,31$ \\
\hline & 2 & $22.47 \pm 2.03 *$ & $17,07 \pm 2,23 *$ & $1,60 \pm 0,41$ & $1,39 \pm 0,61$ & $1,07 \pm 0,23$ & $1,33 \pm 0,37$ \\
\hline & 3 & 14.14 $\pm 1.47 \#$ & $8,87 \pm 1,51 \#$ & $1,80 \pm 0,45$ & $1,47 \pm 0,32$ & $0,93 \pm 0,23$ & $1,07 \pm 0,34$ \\
\hline
\end{tabular}




\begin{tabular}{|c|c|c|c|c|c|c|c|}
\hline Day & Groups & $\begin{array}{l}\text { Total } \\
\text { locomotor } \\
\text { activity }\end{array}$ & $\begin{array}{l}\text { Horizontal } \\
\text { locomotor } \\
\text { activity }\end{array}$ & $\begin{array}{l}\text { Vertical } \\
\text { locomotor } \\
\text { activity }\end{array}$ & $\begin{array}{l}\text { Hole-board } \\
\text { exploration }\end{array}$ & $\begin{array}{l}\text { Self- } \\
\text { grooming }\end{array}$ & Defecation \\
\hline & 1 & $19.47 \pm 2.09$ & $15,47 \pm 1,68$ & $1,00 \pm 0,24$ & $2,00 \pm 0,76$ & $0,47 \pm 0,17$ & $0,53 \pm 0,13$ \\
\hline & 2 & $17.6 \pm 1.57$ & $14,27 \pm 1,85$ & $1,20 \pm 0,35$ & $1,27 \pm 0,33$ & $0,73 \pm 0,18$ & $0,13 \pm 0,09$ \\
\hline & 3 & $22.4 \pm 2.34$ & $18,00 \pm 2,22$ & $1,80 \pm 0,49$ & $1,41 \pm 0,34$ & $0,87 \pm 0,24$ & $0,33 \pm 0,13$ \\
\hline & \multicolumn{7}{|c|}{ Second period (minutes $2-3$ ) } \\
\hline & 1 & $18.66 \pm 2.48$ & $13,60 \pm 2,51$ & $1,53 \pm 0,65$ & $1,60 \pm 0,51$ & $1,13 \pm 0,39$ & $0,80 \pm 0,26$ \\
\hline & 2 & $19.01 \pm 5.39$ & $14,47 \pm 5,34$ & $2,07 \pm 0,59$ & $1,27 \pm 0,80$ & $0,87 \pm 0,17$ & $0,53 \pm 0,22$ \\
\hline & 3 & $22.53 \pm 3.04$ & $16,73 \pm 2,83$ & $2,13 \pm 0,67$ & $2,13 \pm 0,52$ & $0,87 \pm 0,22$ & $0,67 \pm 0,19$ \\
\hline
\end{tabular}

Here and in table 2: $p<0.05$ in comparison with *intact mice, \#alcoholized mice.

Also, the alcoholization of animals was accompanied by a drop in the CPAR reproduction level at the $7,14,21$ days (up to $43.7 \%$ of the level of the same indicator in intact mice on day 21) (Table 2).

Table 2. Parameters of conditioned passive avoidance response of intact C57B1/6 mice (1); mice after prolonged ethanol intoxication (2) and mice treated with an $\mathrm{AC}$ inhibitor after simulating alcoholic encephalopathy (3), $(\mathrm{M} \pm \mathrm{SEM})$.

\begin{tabular}{l|c|c}
\multirow{2}{*}{ Day } & Groups & $\begin{array}{c}\text { Percentage of animals with } \\
\text { reflex, \% }\end{array}$ \\
\hline \multirow{7}{*}{7} & 1 & $93,33 \pm 4,63$ \\
\cline { 2 - 3 } & 2 & $66,67 \pm 6,75^{*}$ \\
\cline { 2 - 3 } & 3 & $\mathbf{8 6 , 6 7 \pm 6 , 3 1 \#}$ \\
\hline \multirow{4}{*}{21} & 1 & $66,67 \pm 5,75$ \\
\cline { 2 - 3 } & 2 & $33,33 \pm 6,75^{*}$ \\
\cline { 2 - 3 } & 3 & $\mathbf{5 6 , 6 7 \pm 6 , 2 6 \#}$ \\
\cline { 2 - 3 } & 1 & $53,33 \pm 4,26$ \\
\cline { 2 - 3 } & 2 & $23,33 \pm 5,85^{*}$ \\
\cline { 2 - 3 } & 3 & $\mathbf{4 3 , 3 3} \pm \mathbf{6 , 2 0} \#$
\end{tabular}

The revealed shifts in animal behavior during the first observation period indicated marked changes in their research activity. To a large extent, they were determined by the high anxiety and increased excitability of long-term alcoholized animals [20]. While the increased motor activity of mice in the second period of observation (2-3 minutes) indicated disorders of predominantly cognitive rather than the locomotor activity of the CNS. At the same time, it is obvious that a violation of the mnestic function of the brain played a role in this $[19,20]$.

Thus, long-term ethanol administration was accompanied by the appearance of "persistent" functional disorders of CNS activity, reflecting the severe toxic brain damage characteristic of alcohol-induced encephalopathy [28].

\subsubsection{Histological changes in nervous tissue.}

A histological examination of the brain in animals with ethanol-induced encephalopathy, significant hyperemia of the pia mater, perivascular and pericellular edema of the nervous tissue was observed. A significant number of neurons with hyperchromic and pyknotic nuclei and neurons and vacuole dystrophy and neurons in the state of phagocytosis by microglia were observed. These neuronal changes were particularly pronounced in the hippocampus (Figure 1, A). 
A
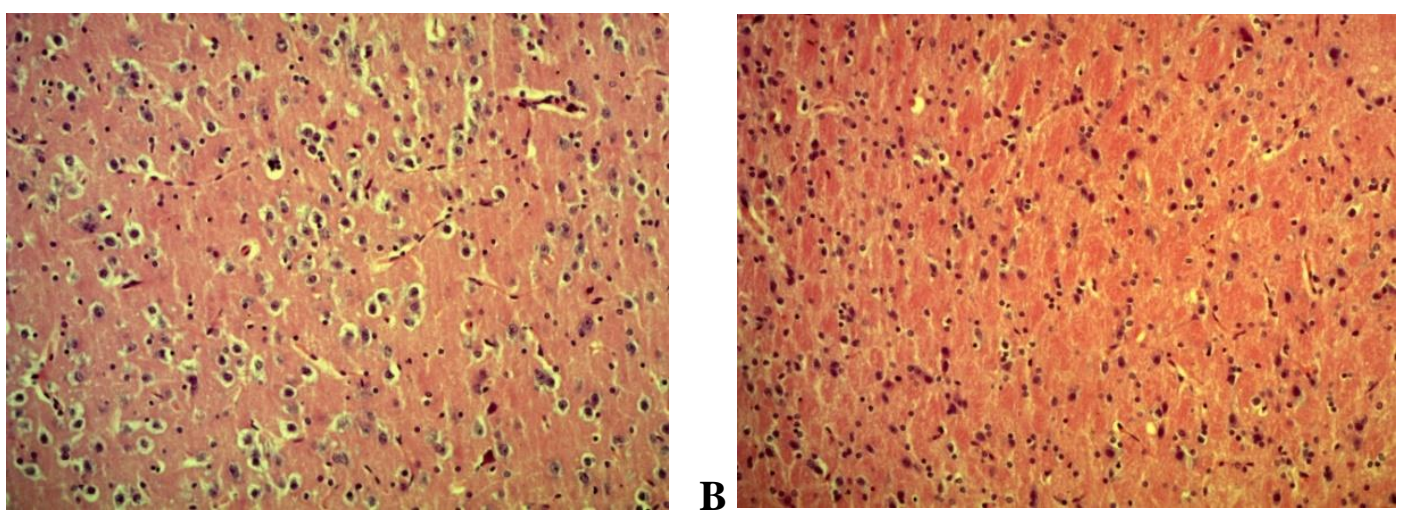

Figure 1. Effects of the AC inhibitor on mice brain on day 7th day after the initiation of the AC inhibitor administration (hematoxylin and eosin staining; magnification $\times 100$ ). (A) alcoholic encephalopathy; (B) alcoholic encephalopathy $+\mathrm{AC}$ inhibitor.

\subsubsection{Content and functional activity of progenitors.}

Administration of ethanol to experimental animals per os led to a decrease in the content of both multipotent NSC (on days 1 and 3) and NCP (on days 1, 3, 14, 21 days) in the SVZ (Figure 2, A; 3, A).
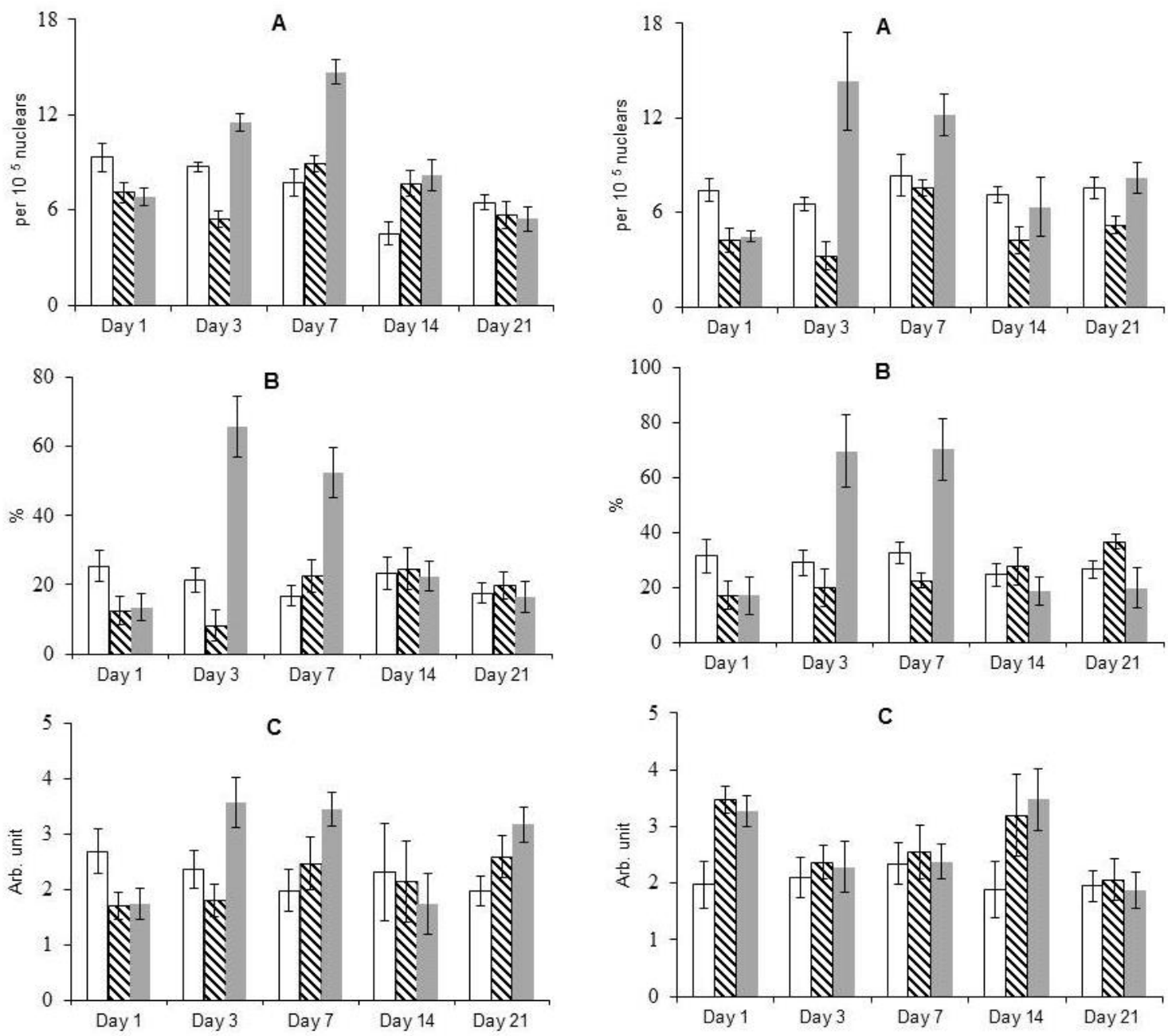

Figure 2. (A) Count of CFU-NNSC; (B) their proliferative activity; (C) differentiation index in the cell culture of the SVZ. Here and in figures 2 and 3: White bars - intact mice; shaded bars alcoholic encephalopathy; grey bars - alcoholic encephalopathy $+\mathrm{AC}$ inhibitor. Confidence intervals at $p=0.05$.

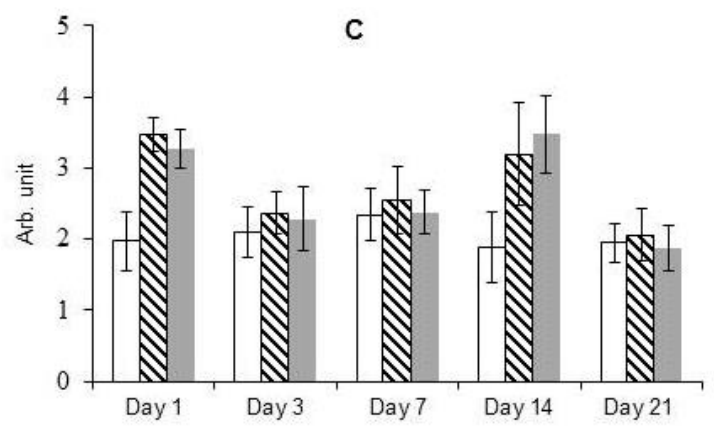

Figure 3. (A) Count of CFU-NPSA-NCAM+; (B) their proliferative activity; (C) differentiation index in the cell culture of the SVZ. 
At the same time, the drop in the number of CFU-NPSA-NCAM+ was longer and significantly more pronounced (up to $49.7 \%$ of the same indicator in intact mice on day 3 ). The lowest amount of CFU-NNSC in the SVZ of alcoholized animals was also recorded on day 3 (62.0\% of the control). The observed dynamics were the result of a drop in proliferative activity of both types of progenitors on days 1 and 3 of the experiment (Figure 2, B; 3, B). At the same time, an increase in the number of NCP in the S-phase of the cell cycle (up to $138.0 \%$ of the level of this parameter in intact mice) was observed on day 21. However, changes in specialization intensity in different types of progenitors were the opposite (Figure 2, C; 3, C). Ethanol-induced neurodegeneration was accompanied by a decrease in the differentiation rate of multipotent NSC (on days 1 and 3) against the background of, in contrast, an acceleration of maturation neuronal-committed progenitors (on days 1 and 14).

Thus, the results of experiments indicate a pronounced failure of the systems of cellular renewal of the CNS in alcohol-induced encephalopathy. At the same time, the identified violations of the realization of the growth potential of progenitors are not directly related to the impact of ethanol on them. The duration of their retention after the end of ethanol administration indicates severe damage to the brain and the formation of a new pattern for regulating its functions $[5,12]$.

\subsubsection{Secretion of neurotrophic growth factors by glial cells.}

The simulations of alcoholic encephalopathy have been accompanied by an increase in the production of neurotrophins stimulating the functions of progenitors of nervous tissues, by astrocytes (on days 1 and 3), and oligodendrocytes (at all study times) (Figure 4, A, B).
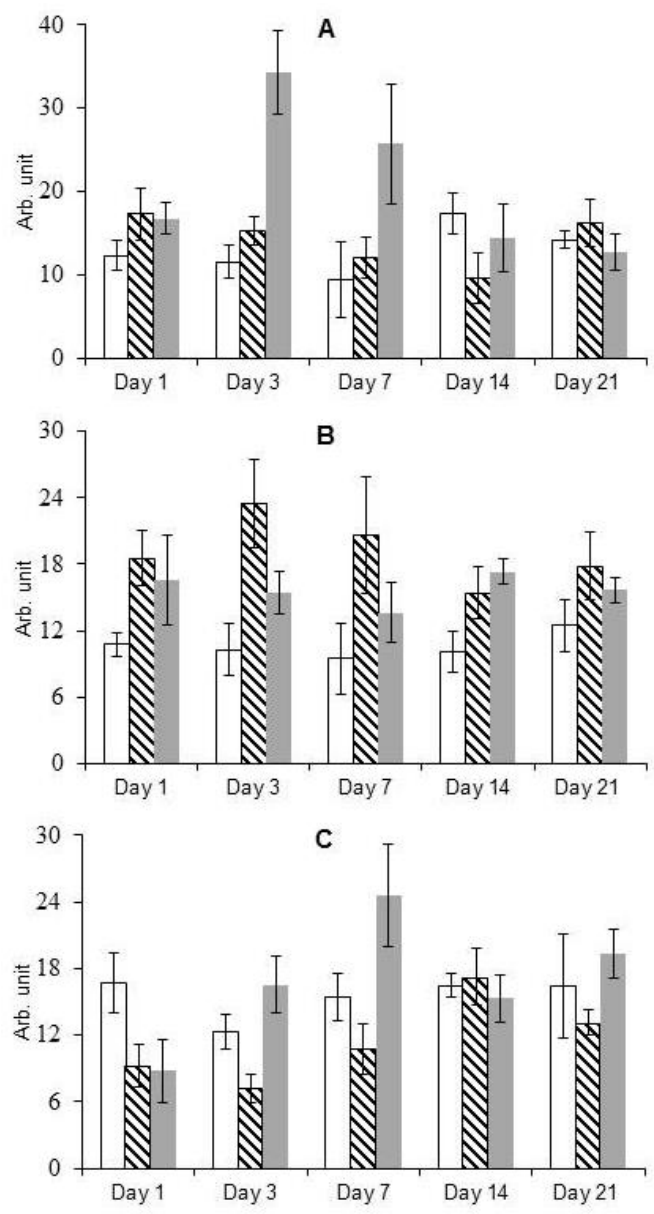

Figure 4. Effect of conditioned media of (A) astrocytes; (B) oligodendrocytes; (C) microglial cells on the level of neurosphere formation in the test system. 
At the same time, the level of changes in the secretory function of $\mathrm{O}^{+}$cells was significantly higher (with a maximum of up to $228.6 \%$ of the same parameter in intact animals on day 3 of observation). Another pattern was recorded by microglia. Neurodegeneration has resulted in a significant reduction in the production of growth factors by these immunocompetent cells (up to $55.4 \%, 58.8 \%$, and $70.1 \%$ of intact control on days $1,3,7$, respectively) (Figure 4, C).

The revealed phenomena were a reflection of the compensatory response of macroglia to brain damage by neurotoxic effects $[10,29]$. The detected decrease in the colony-stimulating activity of conditioned media from microglia was probably not associated with their impaired production of neurotrophins but with an increase in the secretion of proinflammatory cytokines (inhibiting the progenitor's proliferation [30]).

\subsection{Effects of the AC inhibitor.}

\subsubsection{Correction of psychoneurological status disorders.}

The AC inhibitor administration significantly corrected the manifestation of functional signs of the brain pathology (Table 1,2). There was a reversal of changes in the estimated research behavior of animals on the 7 and 21 days at both the first and 2-3 minutes of the study (Table 1). On day 14, there was also a restoration of mice's total locomotor and horizontal activity in the open field, but only in the first observation period. Besides, the course use of the AC inhibitor reversed the decrease in CPAR reproduction level in alcoholized mice (Table 2). Statistically significant differences of this score in AC inhibitor-treated mice with such in intact animals were not recorded throughout the study period.

\subsubsection{Correction of nervous tissue histological changes.}

The AC inhibitor therapy of animals with alcohol-induced encephalopathy led to a significant decrease of hyperemia of the pia mater and a reduction in the severity of pericellular and perivascular edema of nervous tissue. In this case, neurons with vacuole dystrophy and neurons in the state of phagocytosis were found in isolated cases, even in the hippocampus (Figure 1, B).

\subsubsection{Changes of content and functional activity of progenitors.}

In the group of animals treated with the AC inhibitor, there was a significant increase in the number of both NSC and CPN in SVZ on days 3 and 7 of observation (Figure 2, A; 3, A). The identified phenomena were based on an increase in their mitotic activity. The amounts of CFU-N NSC and CFU-NPSA-NCAM+ in the S-phase of the cell cycle were highest at 3 and 5 days (up to $799.3 \%$ and $311.7 \%$ of similar rates in untreated mice, respectively) (Figure 2, B; 3, B). Also, the intensity of NSC specialization increased considerably on days 3, 7, 21 after AC inhibitor initiation (with a maximum of up to $151.7 \%$ of control on day 3) (Figure 2, C). Changes in the NCP maturation rate were not recorded (Figure 3, C).

\subsubsection{Changes in secretion of neurotrophic growth factors by glial cells.}

The AC inhibitor administration after modeling ethanol-induced neurodegeneration was accompanied by a marked increase in the secretion of neurotrophic growth factors by astrocytes (7, 14 days) and microglia (3, 7, 21 days). The most significant growth in secretory 
activity of ACSA-2 $2^{+}$cells was observed on day 3 (up to $223.5 \%$ of the control) and of CD11 $\mathrm{b}^{+}$ cells - on day 7 (up to $227.6 \%$ of the control) (Figure 4, A, C). A different pattern was noted on the part of oligodendrocytes. The neurotrophin production by $\mathrm{O}^{+}$cells, in contrast, decreased (to $65.7 \%$ and $66.0 \%$ of similar parameters in mice that did not receive an $\mathrm{AC}$ inhibitor on days 3 and 7, respectively) (Figure 4, B).

In general, the obtained results confirm the data on significant dysfunction of systems of cellular renewal of nervous tissue of "deep reserve" (progenitor cells) under the influence of the biochemical pathogen continuum induced by ethanol in the brain $[6,26]$. This circumstance is one of the main reasons for the irreversible disorganization and dysadaptation of the CNS, accompanied by disorders of its integrative and regulatory activities [5, 7]. Damage to the compartment of regeneration-competent cells makes the process of neurogenesis impossible [9].

The efficiency of stimulation (recovery) of the progenitor's growth potential by modification of intracellular signaling is demonstrated. Evidence from the experiments suggests pronounced neuroprotective and neuroregenerative effects of the AC inhibitor in alcoholic encephalopathy. Blockade of cAMP synthesis in ethanol-induced neurodegeneration leads to rapid morphofunctional brain repair. A wide range of disorders of CNS activity (locomotor activity, research behavior, cognitive and mnestic functions) caused by multitargeted exposure to ethanol and its metabolites are normalized [5, 26]. The key role in the process of restoring the functions of the CNS, in this case, belongs to the repair of nervous tissue due to the synchronized activation of resident multipotent NSC and neuronal-committed precursors (constituting the most mobile cell section for tissue-specific regeneration [6, 12]). The reduced intracellular concentration of cAMP leads to the increased proliferative activity of both types of progenitors and accelerates the differentiation of NSC and the formation of specialized cells [7, 31]. These changes in the realization of the growth potential of progenitors result from the direct stimulating effect of the AC inhibitor on them [17] and an increase in the production of neurotrophic growth factors by astrocytes microglial cells (Figure 5).

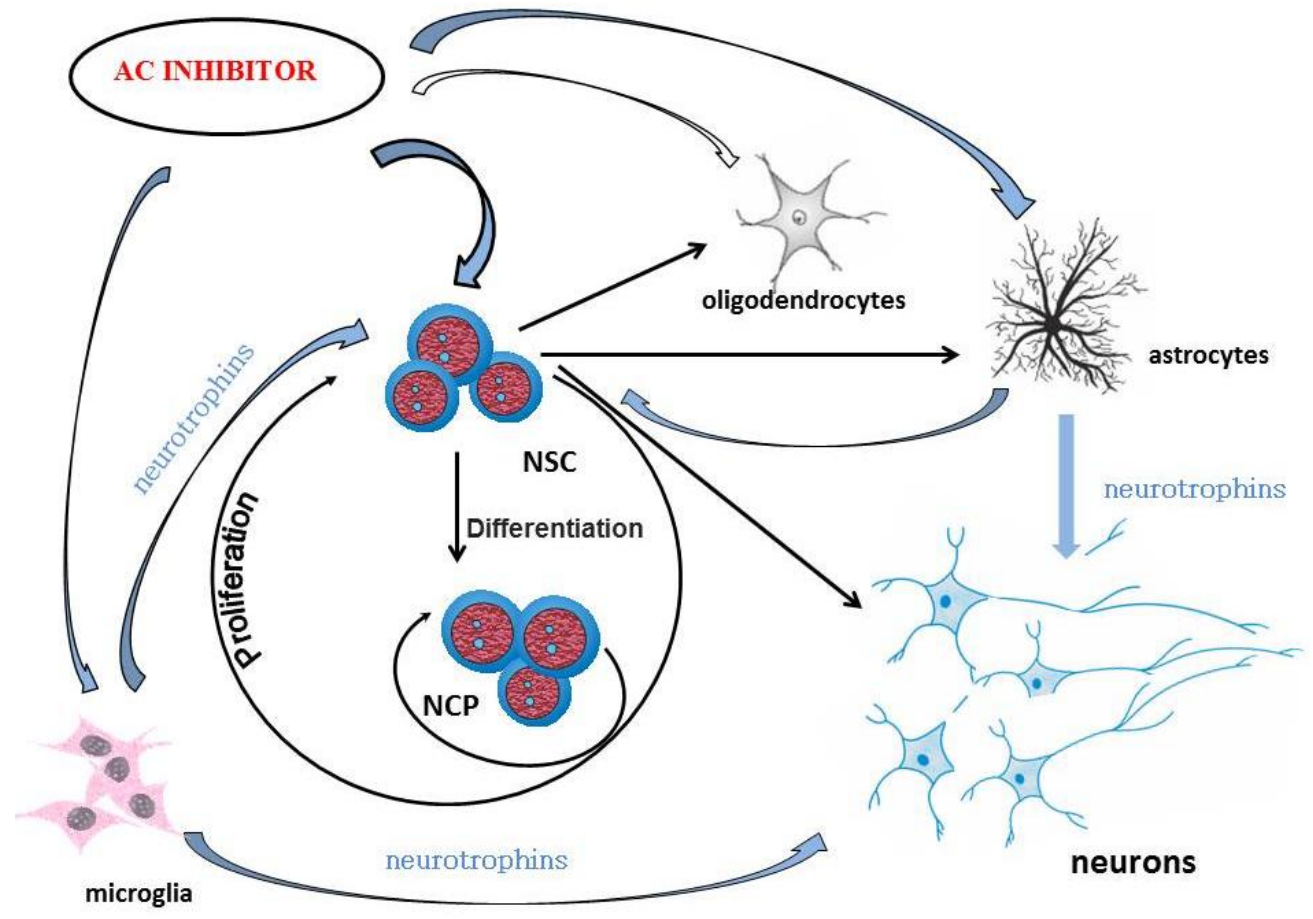

Figure 5. Mechanisms of neuroregenerative action of the AC inhibitor. Blue arrows - stimulating effect; white arrows - inhibitory effect. 
Thus, the neuroregenerative action of the AC inhibitor in alcoholic encephalopathy depends on a coordinated stimulation of the functions of progenitor cells and the neurotrophic activity of astroglia and microglia [32, 33]. It was found that the AC blockade in oligodendrocytes in ethanol-induced neurodegeneration causes a decrease in their secretory activity. However, it is known that the main function of these cells is not in the production of neurotrophins but the myelination [34, 35] and some types of metabolic activity of neurons [36-38]. Therefore, this fact did not affect the integrative effect of humoral support of neuroglia progenitor cells. However, further studies are expected to determine the effect of AC inactivation on the aforementioned oligodendrocytic functions' performance.

\section{Conclusions}

The results show the promise of developing, within the framework of the "Strategy for pharmacological regulation of intracellular signal transduction in regeneration-competent cells" $[5,11,14]$, a novel approach to therapy alcoholic encephalopathy with AC inhibitors.

\section{Funding}

The studies were carried out as part of the execution of the State task of the Ministry of Science and Higher Education of Russia on the topic No. 0550-2019-0011. This work was supported by the Russian Foundation for Basic Research (RFBR) in the framework of scientific project No. 18-015-00013.

\section{Acknowledgments}

We thank the Director of the Goldberg Research Institute of Pharmacology and Regenerative Medicine V.V. Zhdanov, for providing research infrastructure for the work.

\section{Conflicts of Interest}

The authors declare no conflict of interest.

\section{References}

1. Lees, B.; Meredith, L.R.; Kirkland, A.E.; Bryant, B.E.; Squeglia, L.M. Effect of alcohol use on the adolescent brain and behavior. Pharmacology, biochemistry, and behavior 2020, 192, 172906, https://doi.org/10.1016/j.pbb.2020.172906.

2. Koob, G.F.; Colrain I.M. Alcohol use disorder and sleep disturbances: a feed-forward allostatic framework. Neuropsychopharmacology 2020, 45, 141-165, https://doi.org/10.1038/s41386-019-0446-0.

3. Warden, A.S.; Wolfe, S.A.; Khom, S.; Varodayan, F.P.; Patel, R.R.; Steinman, M.Q.; Bajo, M.; Montgomery, S.E.; Vlkolinsky, R.; Nadav, T.; Polis, I.; Roberts, A.J.; Mayfield, R.D.; Harris, R.A.; Roberto, M. Microglia Control Escalation of Drinking in Alcohol-Dependent Mice: Genomic and Synaptic Drivers. Biological psychiatry 2020, 88, 910-921, https://doi.org/10.1016/j.biopsych.2020.05.011.

4. Basu, S.; Suh, H.Role of Hippocampal Neurogenesis in Alcohol Withdrawal Seizures. Brain plasticity 2020, 6, 27-39, https://doi.org/10.3233/BPL-200114.

5. Zyuz'kov, G.N.; Miroshnichenko, L.A.; Simanina, E.V.; Stavrova, L.A.; Polyakova, T.Yu. Intracellular signaling molecules of nerve tissue progenitors as pharmacological targets for treatment of ethanol-induced neurodegeneration. Journal of basic and clinical physiology and pharmacology 2021, https://doi.org/10.1515/JBCPP-2020-0317.

6. Zyuz'kov, G.N.; Miroshnichenko, L.A.; Simanina, E.V.; Polyakova, T.Yu. Prospects for using mitogenactivated protein kinases ERK1/2 and p38 of nerve tissue progenitors as pharmacological targets for the 
treatment of neurodegeneration caused by alcohol. Bulletin of Pharmaceutical Sciences 2020, 43, 217-224, https://doi.org/10.21608/BFSA.2020.127417.

7. Alvarez Cooper, I.; Beecher, K.; Chehrehasa, F.; Belmer, A.; Bartlett, S.E. Tumour Necrosis Factor in Neuroplasticity, Neurogenesis and Alcohol Use Disorder. Brain plasticity 2020, 6, 47-66, https://doi.org/10.3233/BPL-190095.

8. Seemiller, L.R.; Gould, T.J. The effects of adolescent alcohol exposure on learning and related neurobiology in humans and rodents. Neurobiology of learning and memory 2020, 172, 107234, https://doi.org/10.1016/j.nlm.2020.107234.

9. Zyuz'kov, G.N.; Miroshnichenko, L.A.; Udut, E.V.; Chaikovskii, A.V.; T Yu Polyakova, T.Yu.; Simanina, E.V.; Stavrova, L.A.; Agafonov, V. I.; Zhdanov, V.V. Functional State of Various Types of RegenerationCompetent Cells in the Nervous Tissue in Ethanol-Induced Neurodegeneration. Bulletin of Experimental Biology and Medicine 2019, 166, 317-320, https://doi.org/10.1007/s10517-019-04341-2.

10. Chang, H.M.; Wu, H.C.; Sun, Z.G.; Lian, F.; Leung P.C.K. Neurotrophins and glial cell line-derived neurotrophic factor in the ovary: physiological and pathophysiological implications. Human reproduction update 2019, 25, 224-242, https://doi.org/10.1093/humupd/dmy047.

11. Amidfar, M.; de Oliveira, J.; Kucharska, E.; Budni, J.; Kim, Y.K. The role of CREB and BDNF in neurobiology and treatment of Alzheimer's disease. Life sciences 2020, 15, 257:118020, https://doi.org/10.1016/j.lfs.2020.118020.

12. Zyuz'kov, G.N.; Miroshnichenko, L.A.; Polyakova, T.Yu.; Zhdanov, V.V.; Simanina, E.V.; Stavrova, L.A.; Danilets, M.G. Specific Features of Intracellular Signal Transduction in the Regulation of Functions of Neural Stem Cells and Committed Neuronal Progenitors. Bulletin of Experimental Biology and Medicine 2020, 170, 522-527, https://doi.org/10.1007/s10517-021-05100-y.

13. Wang, X.; Liu, H.; Morstein, J.; Novak, A.J.E.; Trauner, D.; Xiong, Q.; Yu, Y.; Ge, S. Metabolic tuning of inhibition regulates hippocampal neurogenesis in the adult brain. Proceedings of the National Academy of Sciences of the United States of America 2020, 117, 25818-25829, https://doi.org/10.1073/pnas.2006138117.

14. Zyuz`kov, G.N.; Zhdanov, V.V.; Udut, E.V.; Miroshnichenko, L.A.; Polyakova, T.Yu.; Stavrova, L.A.; Udut, V.V. Strategy of Pharmacological Regulation of Intracellular Signal Transduction in RegenerationCompetent Cells. Bulletin of Experimental Biology and Medicine 2019, 166, 448-455, https://doi.org/10.1007/s10517-019-04370-x.

15. Boccaccio, A.; Menini, A.; Pifferi, S. The cyclic AMP signaling pathway in the rodent main olfactory system. Cell and tissue research 2021, 383, 429-443, https://doi.org/10.1007/s00441-020-03391-7.

16. Zyuz'kov, G.N.; Miroshnichenko, L.A.; Polyakova, T.Yu.; Stavrova, L.A.; Simanina, E.V. Wound healing properties of the protein kinase A inhibitor and the mechanisms of their development. Bangladesh journal of pharmacology 2021, 16, 34-41, https://doi.org/10.3329/bjp.v16i1.50575.

17. Zyuz'kov, G.N.; Miroshnichenko, L.A.; Polyakova, T.Yu.; Stavrova, L.A.; Simanina, E.V.; Agafonov, V.I.; Zhdanov, V.V. Participation of cAMP/PKA-Mediated Signaling Pathways in Functional Activity of Regeneration-Competent Cells in the Nervous Tissue under Conditions of Ethanol-Induced Neurodegeneration. Bulletin of Experimental Biology and Medicine 2019, 167, 723-727, https://doi.org/10.1007/s10517-019-04608-8.

18. Zyuz'kov, G.N.; Suslov, N.I.; Povet'eva, T.N.; Nesterova, Yu.V.; Afanas'eva, O.G.; Udut, E.V.; Miroshnichenko, L.A.; Simanina, E.V.; Polyakova, T.Yu.; Stavrova, L.A.; Chaikovskii, A.V.; Kul'pin, P.V.; Udut, V.V.; Dygai, A.M.; Zhdanov, V.V. Psychopharmacological Effects of JNK Inhibitor in Posthypoxic Encephalopathy and Mechanisms of Their Development. Bulletin of Experimental Biology and Medicine 2017, 163, 18-21, https://doi.org/10.1007/s10517-017-3727-9.

19. Zyuz'kov, G.N.; Suslov, N.I.; Losev, E.A.; Ermolaeva, L.A.; Zhdanov, V.V.; Udut, E.V.; Miroshnichenko, L.A.; Simanina, E.V.; Demkin, V.P.; Povet'eva, T.N.; Nesterova, Yu.V.; Udut, V.V.; Minakova, M.Yu.; Dygai, A.M. Cerebroprotective and Regenerative Effects of Alkaloid Z77 under Conditions of Brain Ischemia. Bulletin of Experimental Biology and Medicine 2015, 158, 352-354, https://doi.org/10.1007/s10517-015-2760-9.

20. Zyuz'kov, G.N.; Suslov, N.I.; Losev, E.A.; Zhdanov, V.V.; Udut, E.V.; Miroshnichenko, L.A.; Simanina, E.V.; Povet'eva, T.N.; Nesterova, Yu.V.; Udut, V.V.; Minakova, M.Yu.; Zamoshchina, T.A.; Dygai, A.M. Mechanisms of Psychopharmacological Effects of Alkaloid Z77 Under Conditions of Brain Ischemia. Bulletin of Experimental Biology and Medicine 2015, 158, 762-765, https://doi.org/10.1007/s10517-0152856-2. 
21. Teissier, T.; Boulanger, E.; Deramecourt, V. Normal ageing of the brain: Histological and biological aspects. Revue neurologique 2020, 176, 649-660, https://doi.org/10.1016/j.neurol.2020.03.017.

22. Kumar, A.; Pareek, V.; Faiq, M.A.; Kumar, P.; Kumari, C.; Singh, H.N.; Ghosh, S.K. Transcriptomic analysis of the signature of neurogenesis in human hippocampus suggests restricted progenitor cell progression postchildhood. IBRO reports 2020, 9, 224-232, https://doi.org/10.1016/j.ibror.2020.08.003.

23. Kantzer, C.G.; Boutin, C.; Herzig, I.D.; Wittwer, C.; Reiß, S.; Tiveron, M.C.; Drewes, J.; Rockel, T.D.; Ohlig, S.; Ninkovic, J.; Cremer, H.; Pennartz, S.; Jungblut, M.; Bosio, A. Anti-ACSA-2 defines a novel monoclonal antibody for prospective isolation of living neonatal and adult astrocytes. Glia, 2017, 65, 990-1004, https://doi.org/10.1002/glia.23140.

24. Werneburg, S.; Fuchs, H.L.S.; Albers, I.; Burkhardt, H.; Gudi, V.; Skripuletz, T.; Stangel, M.; GerardySchahn, R.; Hildebrandt, H. Polysialylation at Early Stages of Oligodendrocyte Differentiation Promotes Myelin Repair. The Journal of neuroscience: the official journal of the Society for Neuroscience 2017, 37, 8131-8141, https://doi.org/10.1523/JNEUROSCI.1147-17.2017.

25. Martin, E.; El-Behi, M.; Fontaine, B.; Delarasse, C. Analysis of Microglia and Monocyte-derived Macrophages from the Central Nervous System by Flow Cytometry. Journal of visualized experiments: JoVE 2017, 22, 55781, https://doi.org/10.3791/55781.

26. Zyuz’kov, G.N.; Miroshnichenko, L.A.; Polyakova, T.Y.; Zhdanov, V.V.; Simanina, E. V.; Stavrova, L.A. The Role of NF- $\kappa \mathrm{B}$ in the Realization of Functions of Various Types of Regeneration-Competent Cells of the Nervous Tissue in Ethanol-Induced Neurodegeneration. Bulletin of Experimental Biology and Medicine 2020, 169, 759-764, https://doi.org/10.1007/s10517-020-04973-9.

27. Curtis, M.J.; Bond, R.A.; Spina, D.; Ahluwalia, A.; Alexander, S.P.; Giembycz, M.A. Experimental design and analysis and theirreporting: new guidance for publication in BJP. British journal of pharmacology 2015, 172, 3461-3471, https://doi.org/10.1111/bph.12856.

28. Adkins, A.E.; Hack, L.M.; Bigdeli, T.B.; Williamson, V.S.; McMichael, G.O.; Mamdani, M.; Edwards, A.C.; Aliev, F.; Chan, R.F.; Bhandari, P.; Raabe, R.C.; Alaimo, J.T.; Blackwell, G.G.; Moscati, A.; Poland, R.S.; Rood, B.; Patterson, D.G.; Walsh, D.; Whitfield, J.B.; Zhu, G.; Montgomery, G.W.; Henders, A.K.; Martin, N.G.; Heath, A.C.; Madden, P.A.F.; Frank, J.; Ridinger, M.; Wodarz, N.; Soyka, M.; Zill, P.; Ising, M.; Nöthen, M.M.; Kiefer, F.; Rietschel, M.; Gelernter, J.; Sherva, R.; Koesterer, R.; Almasy, L.; Zhao, H.; Kranzler, H.R.; Farrer, L.A.; Maher, B.S.; Prescott, C.A.; Dick, D.M.; Bacanu, S.A.; Mathies, L.D.; Davies, A.G.; Vladimirov, V.I.; Grotewiel, M.; Bowers, M.S.; Bettinger, J.C.; Webb, B.T.; Miles, M.F.; Kendler, K.S.; Riley, B.P. Genomewide Association Study of Alcohol Dependence Identifies Risk Loci Altering Ethanol-Response Behaviors in Model Organisms. Alcoholism, clinical and experimental research 2017, 41, 911-928, https://doi.org/10.1111/acer.13362.

29. Cserép, C.; Pósfai, B.; Dénes, Á. Shaping Neuronal Fate: Functional Heterogeneity of Direct MicrogliaNeuron Interactions. Neuron 2021, 109, 222-240, https://doi.org/10.1016/j.neuron.2020.11.007.

30. Hu, Z.; Deng, N.; Liu, K.; Zhou, N.; Sun, Y.; Zeng, W. CNTF-STAT3-IL-6 Axis Mediates Neuroinflammatory Cascade across Schwann Cell-Neuron-Microglia. Cell reports 2020, 31, 107657 , https://doi.org/10.1016/j.celrep.2020.107657.

31. Keilhoff, G.; Mbou, R.P.; Lucas, B. Differentiation of NSC-34 cells is characterized by expression of NGF receptor p75, glutaminase and NCAM L1, activation of mitochondria, and sensitivity to fatty acid intervention. Acta histochemica 2020, 122, 151574, https://doi.org/10.1016/j.acthis.2020.151574.

32. Guttenplan, K.A.; Liddelow, S.A. Astrocytes and microglia: Models and tools. The Journal of experimental medicine 2019, 216, 71-83, https://doi.org/10.1084/jem.20180200.

33. Wu, A.G.; Zhou, X.G.; Qiao, G.; Yu, L.; Tang, Y.; Yan, L.; Qiu, W.Q.; Pan, R.; Yu, C.L.; Law, B.Y.; Qin, D.L.; Wu, J.M. Targeting microglial autophagic degradation in NLRP3 inflammasome-mediated neurodegenerative diseases. Ageing research reviews 2021, 65, 101202, https://doi.org/10.1016/j.arr.2020.101202.

34. Kuhn; S.; Gritti; L.; Crooks; D.; Dombrowski; Y. Oligodendrocytes in Development; Myelin Generation and Beyond. Cells 2019, 8, 1424, https://doi.org/10.3390/cells8111424.

35. Xin, W.; Chan, J.R. Myelin plasticity: sculpting circuits in learning and memory. Nature reviews. Neuroscience 2020, 21, 682-694, https://doi.org/10.1038/s41583-020-00379-8.

36. Zhou, B.; Zhu, Z.; Ransom, B.R.; Tong, X. Oligodendrocyte lineage cells and depression. Molecular psychiatry 2021, 26, 103-117, https://doi.org/10.1038/s41380-020-00930-0.

37. Philips; T.; Rothstein; J.D. Oligodendroglia: metabolic supporters of neurons. The Journal of clinical investigation 2017, 127, 3271-3280, https://doi.org/10.1172/JCI90610. 
38. Nocera, G.; Jacob, C. Mechanisms of Schwann cell plasticity involved in peripheral nerve repair after injury. Cellular and molecular life sciences: CMLS 2020, 77, 3977-3989, https://doi.org/10.1007/s00018-02003516-9. 